\title{
Molecular characterization and infectivity of a Tomato leaf curl New Delhi virus variant associated with newly emerging yellow mosaic disease of eggplant in India
}

\author{
Dharmendra Pratap ${ }^{1}$, Ashwin R Kashikar ${ }^{2}$ and Sunil K Mukherjee ${ }^{1^{*}}$
}

\begin{abstract}
Background: Begomoviruses have emerged as serious problem for vegetable and fiber crops in the recent past, frequently in tropical and subtropical region of the world. The association of begomovirus with eggplant yellow mosaic disease is hitherto unknown apart from one report from Thailand. A survey in Nagpur, Central India, in 2009-2010 showed severe incidence of eggplant yellow mosaic disease. Here, we have identified and characterized a begomovirus responsible for the newly emerging yellow mosaic disease of eggplant in India.

Results: The complete DNA-A and DNA-B genomic components of the causative virus were cloned and sequenced. Nucleotide sequence analysis of DNA-A showed that it shared highest $97.6 \%$ identity with Tomato leaf curl New Delhi virus-India[India:Udaipur:Okra:2007] and lowest 87.9\% identity with Tomato leaf curl New Delhi virusIndia[India:NewDelhi:Papaya:2005], while DNA-B showed highest 94.1\% identity with ToLCNDV-IN[IN:UD:Ok:07] and lowest $76.2 \%$ identity with ToLCNDV-India[India:Lucknow]. Thus, it appears that this begomovirus is a variant of ubiquitous ToLCNDV and hence, we suggest the name ToLCNDV-India[India:Nagpur:Eggplant:2009] for this variant. The pathogenicity of ToLCNDV-IN[IN:Nag:Egg:09] isolate was confirmed by agroinfiltraion and dimeric clones of DNA-A and DNA-B induced characteristic yellow mosaic symptoms in eggplants and leaf curling in tomato plants.

Conclusion: This is the first report of a ToLCNDV variant moving to a new agriculturally important host, eggplant and causing yellow mosaic disease. This is also a first experimental demonstration of Koch's postulate for a begomovirus associated with eggplant yellow mosaic disease.
\end{abstract}

Keywords: Eggplant yellow mosaic disease, Begomovirus, Tomato leaf curl New Delhi virus, Betasatellite DNA, Agroinfiltration

\section{Background}

Geminiviruses (family Geminiviridae) possess monopartite or bipartite circular, single-stranded DNA genomes encapsidated in geminate (18-22 nm diameters) particles. They infect a wide range of monocotyledonous and dicotyledonous plants but each member of the Geminiviridae family has its own limited host range. They are classified into four genera: Mastrevirus, Curtovirus, Topocuvirus and Begomovirus, on the basis of their

\footnotetext{
* Correspondence: sunilm@icgeb.res.in

'Plant Molecular Biology, International Centre for Genetic Engineering and Biotechnology, Aruna Asaf Ali Marg, New Delhi 110067, India

Full list of author information is available at the end of the article
}

genome organization, host range and insect vector $[1,2]$. A large number of important diseases are caused by begomoviruses, which comprises of more than 180 species [1]. Begomoviruses are transmitted by whitefly Bemisia tabaci (Gennadius) predominantly in the tropical and subtropical regions of the world and cause severe disease in dicot plants including tomato, pepper, cassava, beans, cotton and cucurbits [3-5].

The majority of the begomoviruses are bipartite and the genomic components are referred as DNA-A and DNA-B $[1,6]$. DNA-A encodes the replication-associated protein (Rep) which is essential for viral replication; the replication enhancer protein (REn); the transactivator

\section{C) Biomed Central}


protein (TrAP) that controls late gene expression and involved in RNAi suppression; and the coat protein (CP) for encapsidation and insect transmission. The DNA-B encodes the nuclear shuttle protein (NSP) and the movement protein (MP), both of which are vital in systemic spread and symptom expression. The two genomic components share a common region (CR) that contains motifs required for the control of gene expression and initiation of replication. CR has conserved reiterated motifs and a putative stem-loop structure containing the highly conserved nonanucleotide TAATATT $\downarrow$ AC, which is nicked by the Rep protein to initiate the rolling circle replication $[7,8]$. However, a few Old World begomoviruses such as Tomato leaf curl virus (ToLCV) and Tomato yellow leaf curl virus (TYLCV) are monopartite and have single genomic component, homologous to DNA-A of the bipartite begomoviruses. These monopartite viruses require only DNA-A to cause systemic infection [9-11].

In the recent past, novel satellite molecules called betasatellites (formerly known as DNA- $\beta$ ), were found to be associated with some monopartite begomoviruses such as Cotton leaf curl Multan virus (CLCuMV), which is responsible in the latest disease epidemic of cotton in Pakistan [12]. Betasatellites ( 1.4 kb) have sequences unrelated to those of their helper begomoviruses but intriguingly, they depend on helper virus for replication, transmission and spread $[13,14]$. Betasatellites encode a single gene $\beta C 1$, which is known to be a gene silencing suppressor [15]. Betasatellite is also known to play an important role in determining the host range of its associated begomovirus $[14,16,17]$. Some of the betasatellite molecules have relaxed trans-replication characteristics [18] and it has also been established that association of betasatellite increases disease severity and reduces the period between inoculation and appearance of symptoms [19]. It has also been shown that betasatellite can replace the movement function of DNA-B in case of bipartite begomoviruses [20].

Eggplant (Solanum melongena L.) commonly known as brinjal in India, is an economically important vegetable crop. The production of eggplant is severely affected by a number of plant viruses, particularly the RNA viruses [21]. Begomovirus association with eggplant is so far unknown except for one report from Thailand [1,22].

The natural occurrence of eggplant yellow mosaic disease (EYMD) was observed in a survey conducted in and around Nagpur region of Central India during 2009-2010 and the disease incidence was found to be around $60-65 \%$. The disease prevails across the year and there is no significant seasonal variation about the severity of disease incidence. Infected plants showed severe yellow mosaic and mottling of leaves at later stage of infection. As the presence of whiteflies in the infected fields was noticed, we wanted to explore the possible association of begomoviruses with the EYMD in central India. We employed rolling circle amplification (RCA) technique to identify the infecting begomovirus. Our results revealed the clear association of a ToLCNDV isolate with EYMD in India.

Furthermore, we constructed dimeric agroinfectious clones from isolated genomic components and observed successful infectivity of these agro-clones in eggplants as well as in tomato plants. We have also recorded the period of disease appearance, symptom severity and accumulation of virus in the agroinfiltrated plants. We were also interested to investigate the degree of disease severity when the non-cognate betasatellite is infiltrated along with both the genomic components of the virus and for the purpose, the dimeric clone of non cognate betasatellite (CLCuMV) was used. To the best of our knowledge, this is the first record of a ToLCNDV variant moving to a new host, eggplant and causing EYMD in India and we have artificially simulated the new emerging disease thereby satisfying Koch's postulates.

\section{Methods}

\section{Genomic DNA isolation}

Different leaf samples of eggplant showing yellow mosaic symptoms were collected from various locations of Nagpur in Central India. From the fields surveyed, infected leaf samples from many different plants were collected and used for genomic DNA isolation. Total genomic DNA was isolated from infected samples by Cetyltrimethylammonium bromide (CTAB) method [23].

\section{Full length genomic amplification}

Full length viral genomes (DNA-A and DNA-B) were amplified from the DNA isolated above using RCA [24] based TempliPhi ${ }^{\mathrm{TM}}$ DNA amplification kit (GE Healthcare). RCA reaction was performed as per manufacturer's instruction. The concatemers produced in the reaction were monomerized by restriction digestion with suitable restriction enzymes.

\section{Cloning and sequencing}

Aliquots of $1 \mu \mathrm{l}$ of the above RCA products were digested independently with various restriction enzymes: BamHI, ClaI, EcoRI, HindIII, EcoRV, SacI, and NcoI. Digested products were resolved on $1 \%$ agarose gel and the bands corresponding to $\sim 2.7 \mathrm{~kb}$ genomes were purified using Hi Yield ${ }^{\mathrm{TM}}$ Gel/PCR DNA Mini Kit. The 2.7 $\mathrm{kb}$ monomers (A or B) were cloned into the respective sites of pGreen 0029 vector and henceforth, designated as pGreen-1.0A ( $\mathrm{SacI}$ ) or pGreen-1.0B (XbaI). Monomeric full length clones were purified using HiYield ${ }^{\mathrm{TM}}$ Plasmid Mini Kit. Sequences of the recombinant clones were determined commercially by TCGA Company, 
India. We also investigated for any possible presence DNA- $\beta$ satellite molecule in infected samples by RCA and also by Polymerase chain reaction (PCR) using the universal betasatellite primers, namely, Beta 01 and Beta $02[25]$.

\section{Sequence analysis}

Sequences of all the monomeric clones were assembled and analyzed using the software BIOEDIT version 7.0 programs [26]. Database searches with begomovirus sequences were carried out by NCBI-BLAST program (http://blast.ncbi.nlm.nih.gov). Nucleotide (nt) and amino acid (aa) sequence alignments were performed using CLUSTALW program using Mac Vector software (v11.1.2; MacVector Inc., USA). The phylogenetic tree was constructed using nucleotide sequences of complete DNA-A and DNA-B of ToLCNDV isolates and other selected begomovirus species reported from India and worldwide. Few other selected begomoviruses causing yellow mosaic disease in different plants were also taken into consideration so as to reveal the relationship of the virus isolate under study with its homologues. The phylogenetic tree was constructed with distance/neighborjoining method with 1000 bootstrap replications and viewed with the help of MacVector suite program 10.5 (Mac Vector Inc, USA).

Construction of agroinfectious clones and their infectivity To check the infectivity of the above virus isolate, we used the high fidelity PCR based strategy for making dimeric clones of both DNA-A and DNA-B. For the purpose, we designed two different sets of abutting primers specific for amplifications of complete DNA-A and DNA-B genomic components of the virus isolate. For DNA-A, forward primer

5'-GAGCTCGTGCAGTTGTCCCCAT-3' and reverse primer

5'-AAGCTTCATAGGGGCTGTCGAAGTTGA-3' were synthesized commercially (IDT, USA). The nucleotides underlined represent the respective restriction sites. We incorporated one natural restriction site $(\mathrm{SacI})$ of the virus in the forward primer and one introduced restriction site (HindIII) in the reverse primer for the ease of cloning. The PCR conditions were as follows: initial denaturation at $94^{\circ} \mathrm{C}, 30$ cycles at $94^{\circ} \mathrm{C}$ for $1 \mathrm{~min}$, annealing for $1 \mathrm{~min}$ at $58^{\circ} \mathrm{C}$, and extension for $3 \mathrm{~min}$ at $72^{\circ} \mathrm{C}$, followed by a final extension of $10 \mathrm{~min}$ at $72^{\circ} \mathrm{C}$. The PCR product was subsequently cloned in pGEM-T Easy vector (Promega) and the clones were confirmed by colony PCR, restriction digestion and sequencing. The $2.7 \mathrm{~kb}$ band, released by digestion with HindIII and SacI from the recombinant pGEM-T Easy clone of DNA-A, was subsequently cloned at the same restriction sites of a binary vector pGreen 0029. This clone was named pG-A'. At the next step, the pGreen-1.0A plasmid DNA was digested with $S a c I$ and the 2.7 viral kb DNA was recloned at the SacI site of pG-A'. In this way, a complete head to tail DNA-A dimer was cloned in pGreen0029 (hereafter called as pGreen-2.0A). Insert integrity and orientation of the dimeric clones of DNAA were confirmed by restriction digestion with DraI, a unique cutter in the viral DNA sequence. Two bands corresponding to 7.3 and $2.7 \mathrm{~kb}$ dropped out following digestion with DraI.

For construction of DNA-B dimeric clone, a similar strategy was adopted. The abutting primers were designed in a similar manner: forward primer 5'-TCTAGAACTCATTTGGTGTC-3' and reverse primer 5'-CT GCAGGAG AGAAACTGCAACTTCT-3'. The nucleotides underlined represent the respective restriction sites. We incorporated one natural restriction site $(X b a \mathrm{I})$ in the forward primer and one introduced restriction site (PstI) in the reverse primer. The PCR conditions were same as described above for DNA-A. The PCR products obtained were subsequently cloned in pGEM-T Easy vector (Promega) and the clones were confirmed by restriction digestion and sequencing. The $2.7 \mathrm{~kb}$ DNA released by digestion with $\mathrm{Xba \textrm {I }}$ and Pst $\mathrm{I}$ from pGEM-T Easy clone of DNA-B was subsequently cloned at the same restriction sites of binary vector pGreen0029. The recombinant clone was named pG-B'. The $2.7 \mathrm{~kb}$ viral DNA of pGreen-1.0B plasmid was subsequently mobilized at the $\mathrm{XbaI}$ site of $\mathrm{pG}-\mathrm{B}$ ' and the final dimeric clone was named pGreen-2.0B. Insert integrity and orientation of clones were confirmed by digestion with the internal cutter ScaI.

pGreen-2.0A and pGreen-2.0B plasmid DNAs were mobilized into competent Agrobacterium tumefaciens strain EHA105 with the helper plasmid pSoup by electroporation method using a Gene Pulser Apparatus[27]. Agrobacterium colonies were confirmed by colony PCR. The primers were designed from the flanking sequences of the inserts in the pGreen vector. Empty binary vector pGreen0029 in Agrobacterium was used as negative control for mock inoculation on control plants. To study the effects by betasatellite in disease severity, we also used dimeric agroinfectious clone of non-cognate CLCUMB betasatellite originated from northwestern India-CLCuMB[IN:ND1:03] [28].

A. tumefaciens cultures were incubated with shaking $(200 \mathrm{rpm})$ at $28^{\circ} \mathrm{C}$ for $48 \mathrm{~h}\left(\mathrm{OD}_{600}=1\right)$ in yeast extract-Manitol (YEM) medium ( $\mathrm{pH}$ 6.8) containing kanamycin $(50 \mu \mathrm{g} / \mathrm{ml})$, rifampicin $(20 \mu \mathrm{g} / \mathrm{ml})$ and chloramphenicol $(34 \mu \mathrm{g} / \mathrm{ml})$. Agrobacterium cells were harvested and resuspended in MES buffer [10 mM 2( $N$-morpholino)ethanesulfonic acid (MES), $10 \mathrm{mM}$ Magnesium chloride $\left.\left(\mathrm{MgCl}_{2}\right)\right]$ and used for agroinfiltration on test plants. 
Eggplant (Solanum melongena cv.Pusa Purple Long) and tomato (Solanum lycopersicum cv. Pusa Ruby) plants were grown in vermiculite inside a temperature controlled glasshouse maintained at $25 \pm 2^{\circ} \mathrm{C}$ and a $16 / 8$ $\mathrm{h}$ light/dark cycle. 5-6 leaf stage eggplant and tomato plants were used for agroinfiltration. All the agroinfectious constructs, pGreen-2.0A, pGreen-2.0B and pBin$2.0 \beta$ were used for infiltration in tomato and eggplants either individually or in various combinations with equimolar concentrations as described earlier [29]. Five plants each of eggplant and tomato plants were used for various combinations of agro-constructs and agroinfiltrated plants were grown in an insect-free glasshouse and the plants were maintained at $16 / 8 \mathrm{~h} \mathrm{light/dark}$ periods for 30 weeks to observe the symptoms periodically.

\section{Analysis of viral DNA in inoculated plants}

Total genomic DNA isolated from agroinfiltrated plants was used as a template for RCA. The templified products were digested with DNA-A specific single cutter restriction enzyme and the digested products were analyzed on agarose gel. Semiquantitative-PCR was also performed using ToLCNDV eggplant isolate DNA-A specific abutting primers to examine the relative viral accumulation efficiency of the virus in infiltrated test plants. The band intensities were quantified using Image J software. The quantified intensity values were normalized with respect to the respective actin controls which was taken as negative control. The value obtained for A $+\mathrm{B}$ was arbitrarily assigned as $100 \%$. The sequence of actin primers and PCR conditions were similar as described earlier [30].

\section{Results}

Field detection of the viral disease and cloning of viral DNA

Eggplants showing severe yellow mosaic symptoms were observed in fields during a survey carried out in 20092010 in central India (Figure 1A, B). To characterize the presence of begomovirus in the infected plants, total DNA was isolated from the leaf samples of infected plants as well as from healthy eggplants (as negative control). RCA was performed with the isolated DNA and the RCA products were digested with different restriction enzymes. The results presented in Figure $1 \mathrm{C}$ clearly demonstrate the presence of $\sim 2.7 \mathrm{~kb}$ product in case of infected samples when digested with HindIII, EcoRI, BamH1, SacI and EcoRV, while no such band appeared on digestion with NcoI. The appearance of $2.7 \mathrm{~kb}$ amplified DNA suggested the presence of a begomovirus in the infected leaves. In healthy leaf samples no band corresponding to $2.7 \mathrm{~kb}$ was observed, as expected. The $2.7 \mathrm{~kb}$ fragments obtained from digestion with above restriction enzymes were directly cloned in pGreen0029 at their respective sites and sequenced. The DNA was extracted separately from the leaves of 15 different infected plants of same neighborhood and subjected to similar treatments of RCA followed by restriction digestion. In every case, similar results were obtained and the amplified and digested DNAs were cloned and sequenced. About twenty clones from the leaf DNA of each infected plant were sequenced.

\section{Viral DNA sequence analysis}

The end sequences (about 700 bases in total), obtained from each of the positive samples, showed the presence
(A)

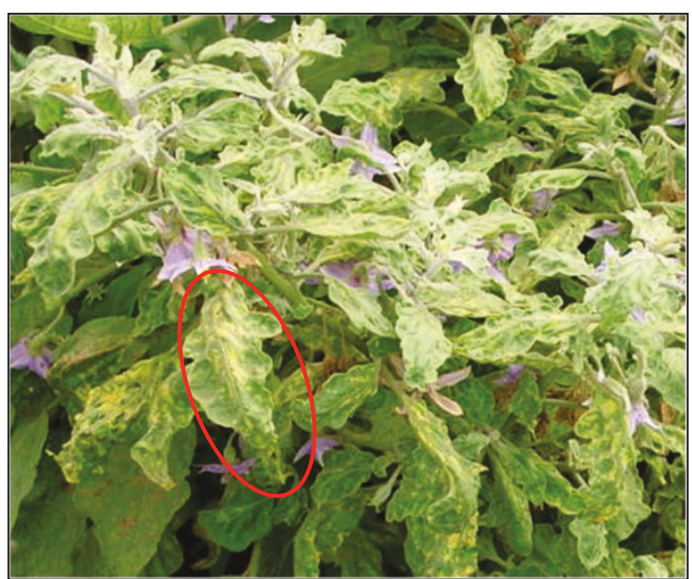

(B)

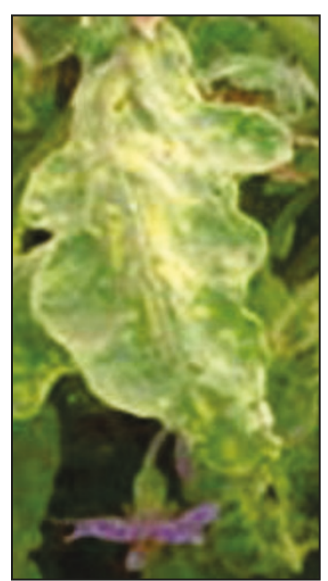

(C)

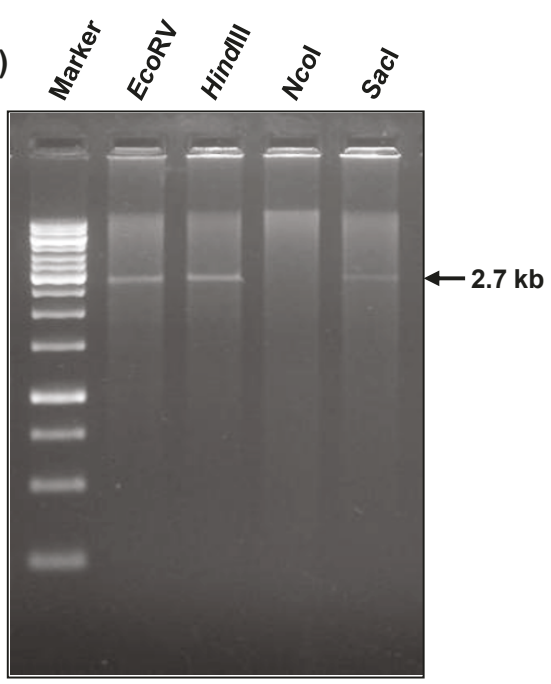

Figure 1 (A) Naturally infected eggplants with yellow mosaic symptoms and mottling of leaves. (B) A magnified image of a part of the diseased leaf [encircled in red (A)]. (C) The profile of restriction digestions of the RCA products of DNA derived from the leaves of naturally infected plants. The DNA marker is shown at the extreme left of the figure. The enzymes used for digestion are indicated at the top of the figure. 
of a bipartite (DNA-A and DNA-B) begomovirus. All DNA-A clones were found to be more than $99 \%$ identical amongst themselves and all the DNA-B clones were also about $97 \%$ identical amongst themselves. Hence, for subsequent studies, only a few clones of each type, i.e., having either DNA-A or DNA-B, were chosen for further characterization of the virus. To sequence the remaining portion of DNA-A and DNA-B, primer walking was carried out by designing additional internal primers. Three clones of each of DNA-A and DNA-B were sequenced completely and one such clone of each DNA-A and DNA-B was used for characterization of the full genome. The restriction enzymes $S a c I$ and EcoRV for DNA-A and HindIII and XbaI for DNA-B were found to be unique cutters. The complete DNA-A and DNA-B sequences are available in GenBank with the accession numbers HQ264185 and HQ264186 respectively. The DNA-A and DNA-B components are comprised of $2741 \mathrm{nt}$ and $2698 \mathrm{nt}$ respectively and their genome organizations are identical to those of the previously characterized bipartite begomoviruses. DNA-A contains six open reading frames (ORFs) of which two ORFs AV1 and AV2 are in the virion sense and the other four ORFs, i.e., $\mathrm{AC} 1, \mathrm{AC} 2, \mathrm{AC} 3$ and $\mathrm{AC} 4$, are in complementary sense. These ORFs are interspersed by $276 \mathrm{nt}$ long intergenic region (IR) located between the ORFs AC1 and AV2. The DNA-B component contains two ORFs designated as BVI on the sense strand and $\mathrm{BC} 1$ on the complementary strand. The DNA-A and DNA-B genomes did not exhibit any sequence similarity, except for approximately $160 \mathrm{nt}$ common region (CR) which showed $\sim 96.8 \%$ sequence identity with each other. In the CR, a 34 bp potential stem-loop forming region (5'-GCGGCCATTCGTATAATATTACCGAATG GCCGCG-3') was identified which includes the conserved nonanucleotide sequence TAATATTAC present within the replication origin of almost all geminiviruses.

The nucleotide sequence comparison of complete DNA-A of the virus isolate with the selected strains of TOLCNDV, TYLCV and other begomoviruses reported from India and worldwide (Table 1) showed highest identity (97.6\%) with ToLCNDV-IN[IN: UD: Ok: 07] and lowest (87.9\%) with ToLCNDV-IN[IN:ND:Pap:05] (Table 2). We thus suggest the name of the variant as ToLCNDV-India[India:Nagpur:Eggplant:2009] in accordance with the latest International Committee on

Table 1 Name, acronym and GenBank accession numbers of the selected begomovirus genome sequences used for study

\begin{tabular}{|c|c|c|c|}
\hline Begomoviruses & DNA-A* & DNA-B* & Acronym \\
\hline Tomato leaf curl New Delhi virus- India [India: New Delhi:2005] & DQ169056 & DQ169057 & ToLCNDV-IN[IN:ND:05] \\
\hline Tomato leaf curl New Delhi virus-India[India:Udaipur:Okra:2007] & EF035482 & EF043394 & ToLCNDV-IN-[IN:UD:Ok:07] \\
\hline Tomato leaf curl New Delhi virus-Bangladesh & EF450316 & NA & ToLCNDV-BD \\
\hline Tomato leaf curl New Delhi virus -OM-Taiwan & GU180095 & GU180096 & ToLCNDV-[OM: Tai] \\
\hline Tomato leaf curl New Delhi virus-Pakistan & EF620534 & EF620535 & ToLCNDV-Pak \\
\hline Tomato leaf curl New Delhi virus - India-186b & GQ865546 & NA & ToLCNDV-IN-186b \\
\hline Tomato leaf curl New Delhi virus [India:Bangalore:OY135:2005] & GU112084 & GU112085 & ToLCNDV-IN[IN: Ban:05] \\
\hline Tomato leaf curl New Delhi virus - India[Pakistan:Solanum nigrum:1997] & AJ620187 & AJ620188 & ToLCNDV-IN[PK: Sn: 97] \\
\hline Tomato leaf curl New Delhi virus- India[India:New Delhi:Severe:1992] & U15015 & U15017 & ToLCNDV-IN[IN: ND: Svr:92] \\
\hline Tomato leaf curl New Delhi virus-India [Bangladesh:Jessore: Severe:2005] & AJ875157 & AJ875158 & ToLCNDV-IN[BG:Jes:Svr:05] \\
\hline Tomato leaf curl New Delhi virus-India [India: Lucknow] & Y16421 & X89653 & ToLCNDV-IN[IN: Luck] \\
\hline Tomato leaf curl New Delhi virus -India [India: Happur: Potato: 2005] & EF043230 & EF043233 & ToLCNDV-IN[IN:Hap:Pot:05] \\
\hline Tomato leaf curl New Delhi virus -India[India: Meerut: Potato: 2005] & EF043231 & EF043232 & ToLCNDV-IN[IN: Mer: Pot: 05] \\
\hline Tomato leaf curl New Delhi virus-Thailand[Cucumber: Thailand] & AB330079 & AB330080 & ToLCNDV-TH[Cuc:Thai] \\
\hline Tomato leaf curl New Delhi virus-India [India: New Delhi: Mild :1992] & U15016 & NA & ToLCNDV-IN[IN: ND: Mld:92] \\
\hline Tomato leaf curl New Delhi virus-Thailand [Luffa:Thailand] & AF102276 & NA & ToLCNDV-TH[TH: Luf] \\
\hline Tomato leaf curl New Delhi virus-India [India: New Delhi:Papaya:2005] & DQ989325 & NA & ToLCNDV-IN[IN:ND:Pap:05] \\
\hline Tomato leaf curl New Delhi virus [India:Aurangabad:OY164A:2006] & GU112088 & GU112089 & ToLCNDV-IN[IN: Aug: 06] \\
\hline Tomato leaf curl New Delhi virus [India:Nagpur:Eggplant:2009] & HQ264185 & HQ264186 & ToLCNDV-IN[IN:Nag:Egg:09] \\
\hline Tomato leaf curl Palampur virus-India & AM884015 & AM992534 & TOLCPMV \\
\hline Squash leaf curl China virus [Pumpkin :Coimbatore] & AY184487 & AY184488 & SLCCV-IN[Pump:Coi] \\
\hline Tomato yellow leaf curl Kanchanaburi virus[Thailand Kanchanaburi 2: Eggplant: 2001] & AF511530 & AF511528 & TYLCKaV-TH[TH:Kan2:Egg:01] \\
\hline Tomato yellow leaf curl Kanchanaburi virus[Vietnam: Binhudong: Eggplant:2005] & DQ641702 & NC_005811 & TYLCKaV-TH[Vn:Bin:Egg:05] \\
\hline
\end{tabular}

The ToLCNDV variant under study is written in bold. 


\begin{tabular}{|c|c|c|}
\hline Virus-Acronym & DNA-A & DNA-B \\
\hline ToLCNDV-IN[IN:UD:Ok:07] & 97.6 & 94.1 \\
\hline ToLCNDV-IN-186b & 97.0 & NA \\
\hline ToLCNDV-IN[IN: Ban:05] & 96.3 & 86.4 \\
\hline ToLCNDV-IN[IN: Aug: 06] & 95.6 & 88.3 \\
\hline ToLCNDV-IN[IN:ND:05] & 94.5 & 86.4 \\
\hline ToLCNDV-IN[PK: Sn: 97] & 94.5 & 82.0 \\
\hline ToLCNDV-IN[IN: ND: Svr:92] & 94.3 & 86.4 \\
\hline ToLCNDV-IN[BG:Jes:Svr:05] & 94.3 & 86.4 \\
\hline ToLCNDV-IN[IN: Luck] & 94.0 & 76.2 \\
\hline ToLCNDV-IN[IN: Mer: Pot: 05] & 93.7 & 86.3 \\
\hline ToLCNDV-Pak & 93.2 & 90.9 \\
\hline ToLCNDV-TH[Cuc:Thai] & 92.7 & 81.4 \\
\hline ToLCNDV-IN[IN: ND: Mld:92] & 92.7 & NA \\
\hline ToLCNDV-[OM: Tai] & 92.1 & 80.6 \\
\hline ToLCNDV-IN[IN:Hap:Pot:05] & 91.4 & 86.7 \\
\hline ToLCNDV-TH[TH: Luf] & 91.1 & NA \\
\hline ToLCNDV-BD & 88.8 & NA \\
\hline ToLCNDV-IN[IN:ND:Pap:05] & 87.9 & NA \\
\hline SLCCV-IN[Pump:Coi] & 86.8 & 63.3 \\
\hline TolCPMV & 85.3 & 68.1 \\
\hline TYLCKaV-TH[Vn:Bin:Egg:05] & 67.3 & 39.0 \\
\hline TYLCKaV-TH[TH:Kan2:Egg:01] & 66.9 & 39.0 \\
\hline
\end{tabular}

\# Information about the sequences used for comparison is provided in Table1 NA-Sequence not available

Taxonomy of Viruses (ICTV) guidelines for species demarcation in the genus [1].

The nucleotide sequence analysis of DNA-B of the ToLCNDV isolate under study with selected DNA-B sequences of begomovirus in NCBI database showed that it has highest sequence identity (94.1\%) with ToLCNDV-IN[IN:UD:Ok:07] and lowest with ToLCNDV-IN[IN: Luck] (Table 2).

The phylogenetic tree analysis on the basis of nucleotide sequence of DNA-A genome of the ToLCNDV-IN [IN:Nag:Egg:09] with the DNA-A sequences of other selected begomoviruses revealed that the ToLCNDV-IN [IN:Nag:Egg:09] isolate has close relationship with the strains of ToLCNDV. In contrast, DNA-A nucleotide sequences of begomovirus species associated with EYMD in Thailand, showed divergent relationship with ToLCNDV-IN[IN: Nag: Egg: 09] isolate (Figure 2). Phylogenetic analysis of the DNA-B genome also showed that ToLCNDV-IN[IN:Nag:Egg:09] isolate has close relationship with ToLCNDV strains (Figure 3).

\section{Infectivity of the cloned genomic components}

To assess the infectivity of the present ToLCNDV isolate, agroinfectious constructs of both the genomes were introduced into the leaves of tomato as well as eggplant using the agro-infiltration technique. Agroinfiltration of various constructs were carried out either individually or in various combinations and the consequent disease expressions are summarized in Table 3. When both the genomic components (DNA-A and DNA-B) were coinfiltrated, typical yellow mosaic symptoms at 60 days post inoculation (dpi) was observed in eggplants $(5 / 5)$ (Figure 4, panels $\mathrm{C}$ and $\mathrm{G}$ ) and the same constructs evoked typical downward leaf curling in tomato plants $(5 / 5)$ at 45 dpi (Figure 5, panels C and G). The symptoms persisted even at 150 and $180 \mathrm{dpi}$ in eggplants and tomato plants respectively.

To investigate the possible role of non-cognate DNA$\beta$ satellite in the disease severity, we co-infiltrated the dimeric clone of betasatellite, CLCuMB[IN:ND1:03] along with both the genome-components of ToLCNDVIN[IN:Nag:Egg:09] on the test plants (eggplant and tomato). The eggplants exhibited severe yellow mosaic symptoms at $45 \mathrm{dpi}$ (Figure 4, panels D and $\mathrm{H}$ ) while severe downward leaf curling was observed in tomato at 30 dpi (Figure 5, panels D and $\mathrm{H}$ ).

The DNA-A genomic component failed to develop disease either in eggplant or tomato when infiltrated alone (Figure 4, panels A and E; Figure 5, panels A and E). In addition, we were also interested to examine that the DNA-B component of the ToLCNDV-IN[IN:Nag: Egg:09] isolate could be replaced by non-cognate CLCuMV DNA- $\beta$ for systemic disease development. As anticipated, co-infiltration of DNA-A and DNA- $\beta$ resulted in successful systemic disease development. The symptoms were mild mosaic in eggplant (2/5) (Figure 4, panels B and F) and leaf curling in tomato plants (3/5) (Figure 5, panels B and F). Thus, non cognate CLCuMV DNA- $\beta$ substituted DNA-B of ToLCNDV-IN[IN:Nag: Egg:09] for systemic viral movement in both eggplant and tomato plants, albeit in a reduced manner. However, the disease expression period was prolonged compared to when the B-component was administered with DNA-A. The symptom development periods were 90 and 80 dpi for eggplant and tomato respectively.

However, the severity of the symptoms was most pronounced when all of the three components, i.e., DNAA/DNA-B/DNA- $\beta$, were co-transferred in plants. Figure 4 shows the severity of yellow mosaic disease in eggplants and the leaves curled with progression of the disease (panels $\mathrm{D}$ and $\mathrm{H}$ ). The disease expression time also reduced to 45 days. Similar was the case with tomato and the curled leaves showed mosaic symptoms eventually due to virus infection (Figure 5, panels $\mathrm{D}$ and $\mathrm{H}$ ). The disease also expressed early, i.e., at about $30 \mathrm{dpi}$ in tomato plants.

As expected, neither empty pGreen vector (negative control) nor DNA-B and DNA- $\beta$ construct caused any 


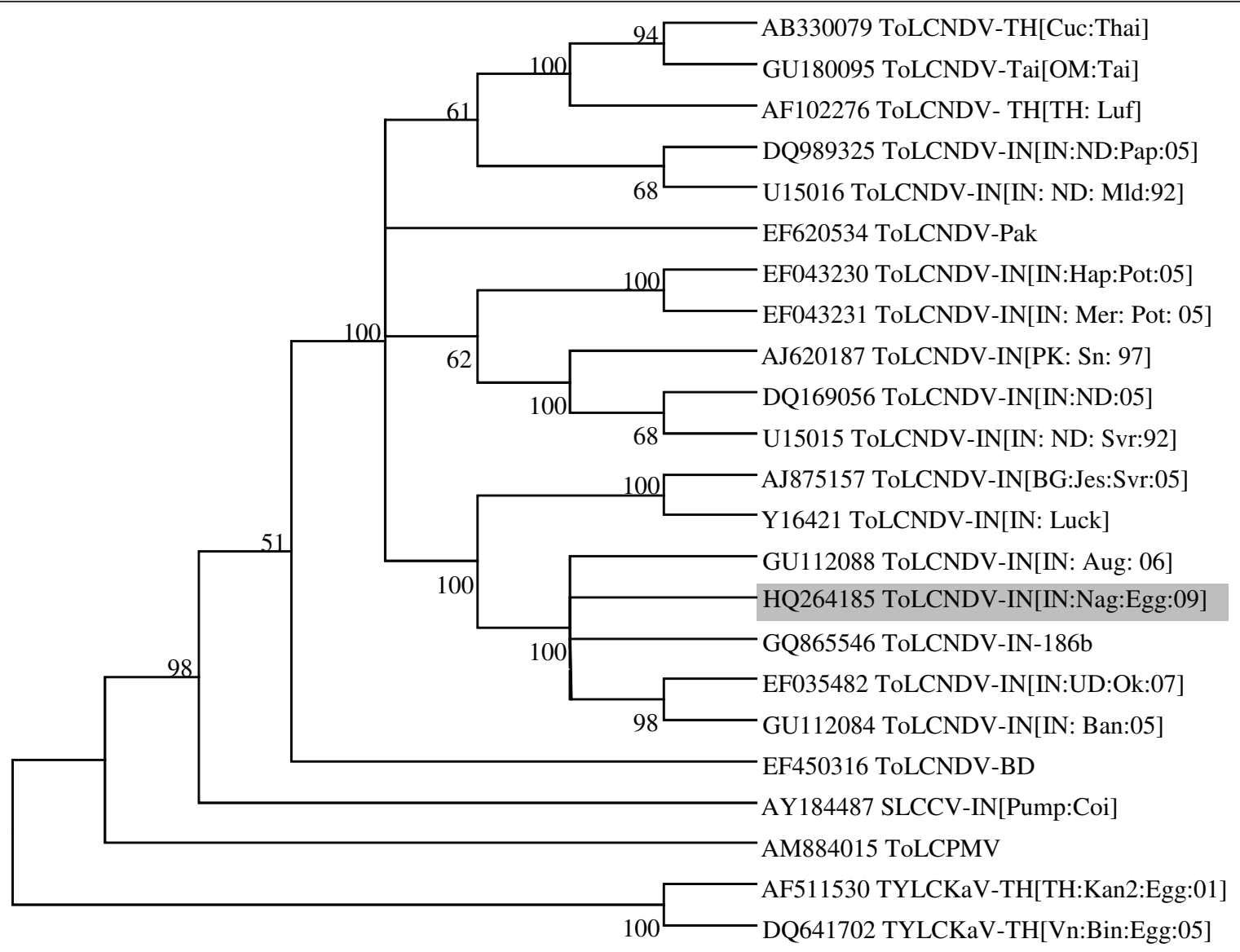

Figure 2 Phylogenetic tree of complete DNA-A of ToLCNDV-IN[IN: Nag: Egg: 09]. The phylogenetic tree was constructed with distance/ neighbour-joining method with 1000 bootstrap replications and viewed with the help of MacVector suite program 10.5 (Mac Vector Inc, USA).

symptoms in test plants even at $180 \mathrm{dpi}$ and no noticeable phenotypic change in eggplant and tomato plants were observed. In contrast, plants infiltrated with the agroinfectious constructs were always stunted in growth.

\section{The level of viral DNA accumulation in the diseased plants}

In order to know the level of viral DNA accumulation, total DNA from systemic and symptomatic leaves of agroinfiltrated eggplant and tomato plants was extracted and subjected to semi-qPCR and RCA. RCA products of high molecular weight were digested with EcoRV, unique site in the DNA-A of ToLCNDV-IN[IN:Nag: Egg:09]. The $2.7 \mathrm{~kb}$ band was observed only in plants agro infiltrated with either both the genomic components or DNA-A with non cognate DNA- $\beta$. However, no such band was observed in plants infiltrated with only DNA-A (data not shown).

The semi-qPCR was carried out to know the level of viral DNA accumulation in plants infiltrated with various constructs. The results revealed that the viral DNA accumulation in tomato plants was highest when the plants were infiltrated with all the three components, namely DNA-A, DNA-B and non cognate DNA- $\beta$. The accumulation of viral DNA was lowest when the DNA-A and DNA- $\beta$ was used for co-infiltration (Figure 6A, C). Similar results were also obtained with eggplants (Figure 6B, D). However, the effects of non cognate $\beta$ DNA was less pronounced in eggplants compared tomato.

The measured intensities of the $2.7 \mathrm{~kb}$ bands were normalized with respect to the corresponding actin controls. The average normalized intensity values (based on three independent studies) are presented as bar graphs in Figure 6C, D. Our data reflect that the accumulation of viral DNA increased to $~ 95 \%$ on introduction of non cognate DNA $\beta$ in tomato while there was a modest increase of $\sim 14 \%$ in eggplant. The accumulation of viral DNA was further reduced up to $\sim 27 \%$ when DNA-B was substituted by non cognate DNA- $\beta$ in tomato plants whereas the same was $\sim 50 \%$ in eggplant (Figure $6 \mathrm{C}, \mathrm{D}$ ).

\section{Discussion}

Eggplant is one of the preferred hosts for rearing of whiteflies and was known to be immune for begomovirus [31] 


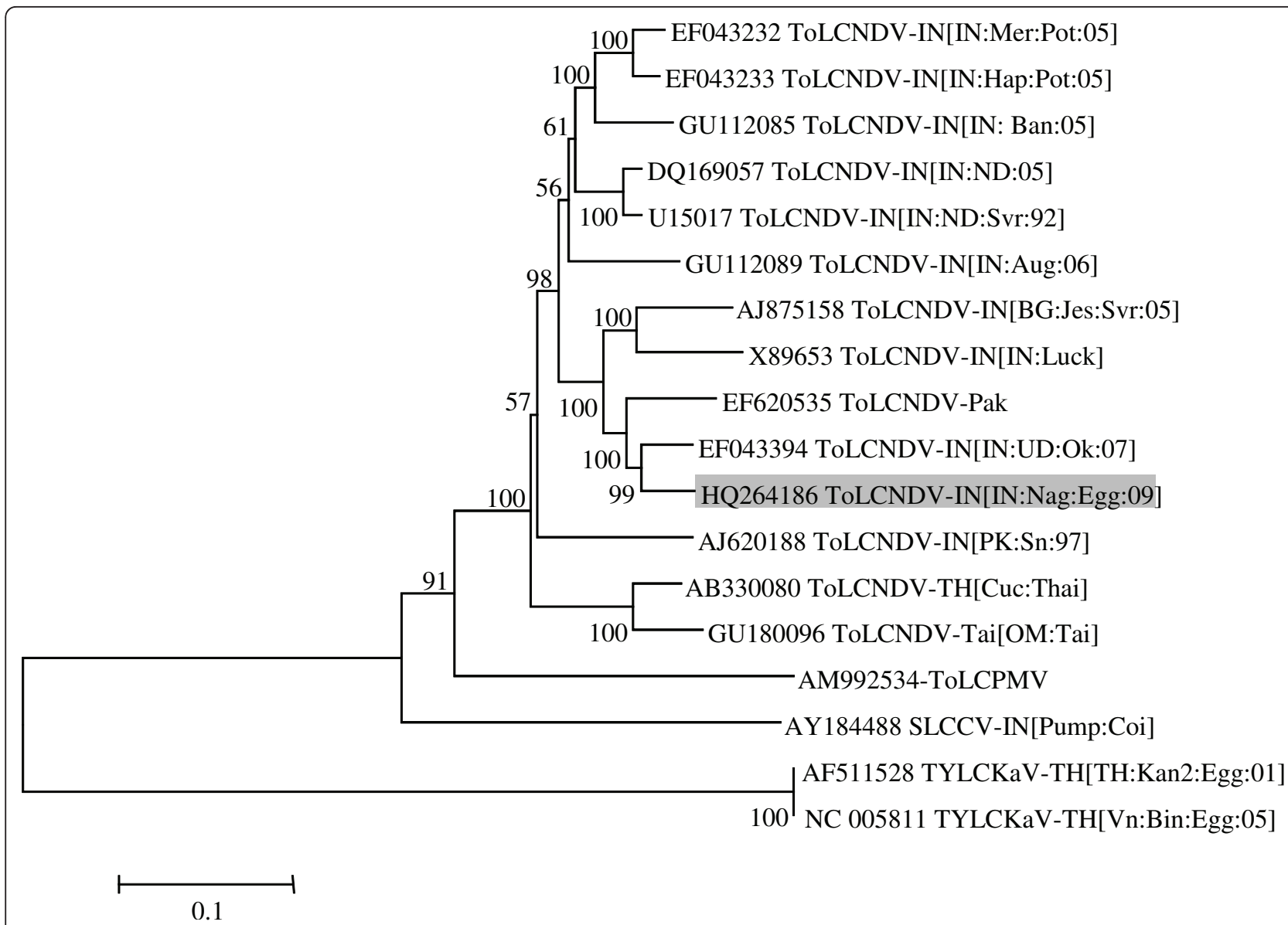

Figure 3 Phylogenetic tree of complete DNA-B of ToLCNDV-IN[IN:Nag:Egg:09]. The phylogenetic tree was constructed with distance/ neighbour-joining method with 1000 bootstrap replications and viewed with the help of MacVector suite program 10.5 (Mac Vector Inc, USA).

Table 3 Infectivity and symptom induced by ToLCNDV-IN[IN:Nag:Egg:09] with or without non-cognate betasatellite CLCUMB-[IN:ND1:03] and the number of symptomatic plants as confirmed by RCA

\begin{tabular}{|c|c|c|}
\hline $\begin{array}{l}\text { Host/Inoculated dimeric } \\
\text { agro-constructs }\end{array}$ & Symptomatic plants/Inoculated plants & $\begin{array}{l}\text { Types of symptoms } \\
\text { (90dpi) }\end{array}$ \\
\hline \multicolumn{3}{|l|}{ Eggplant } \\
\hline DNA-2A & $0 / 5$ & No Symptoms \\
\hline DNA-2A+DNA-2B & $5 / 5$ & Yellow mosaic \\
\hline$D N A-2 A+D N A-2 \beta$ & $3 / 5$ & Mild yellow mosaic \\
\hline$D N A-2 A+D N A-2 B+2 \beta$ & $5 / 5$ & Severe yellow mosaic \\
\hline DNA-2B & $0 / 5$ & No Symptoms \\
\hline DNA-2 $\beta$ & $0 / 5$ & No Symptoms \\
\hline DNA-2B+CLCUMV-DNA-2 $\beta$ & $0 / 5$ & No Symptoms \\
\hline \multicolumn{3}{|l|}{ Tomato } \\
\hline DNA-2A & $0 / 5$ & No Symptoms \\
\hline DNA-2A+ DNA-2B & $5 / 5$ & Leaf curling \\
\hline$D N A-2 A+D N A-2 \beta$ & $4 / 5$ & Mild leaf curling \\
\hline$D N A-2 A+D N A-2 B+D N A-2 \beta$ & $5 / 5$ & Severe leaf curling with occasionally yellow mosaic \\
\hline DNA-2B & $0 / 5$ & No Symptoms \\
\hline DNA2 $\beta$ & $0 / 5$ & No Symptoms \\
\hline $2 B+2 \beta$ & $0 / 5$ & No Symptoms \\
\hline
\end{tabular}




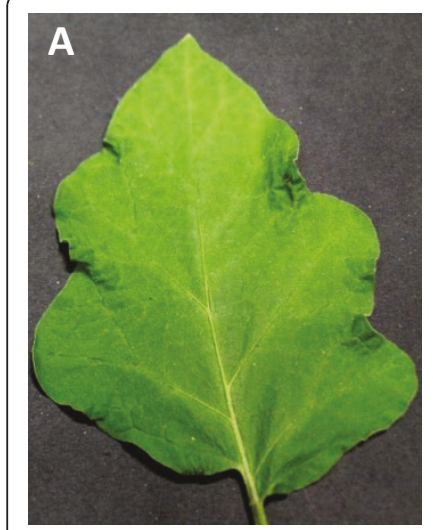

A

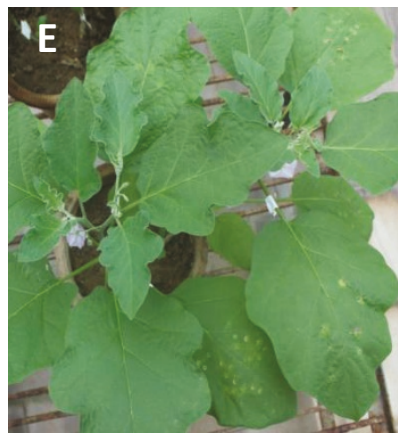

A

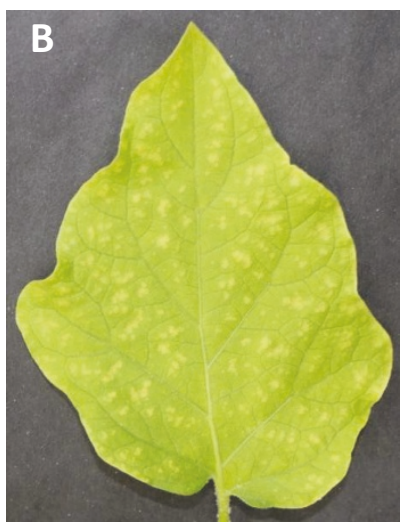

$A+\beta$

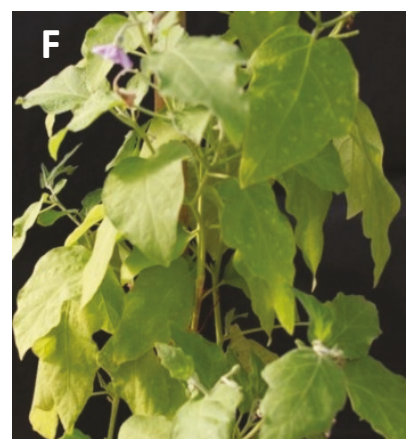

$A+\beta$

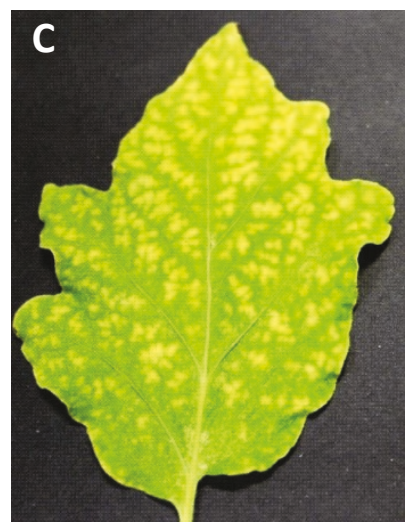

$A+B$

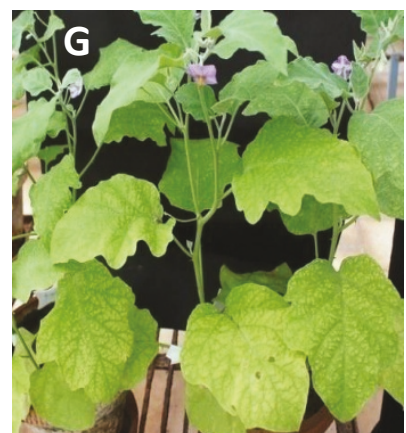

A+B

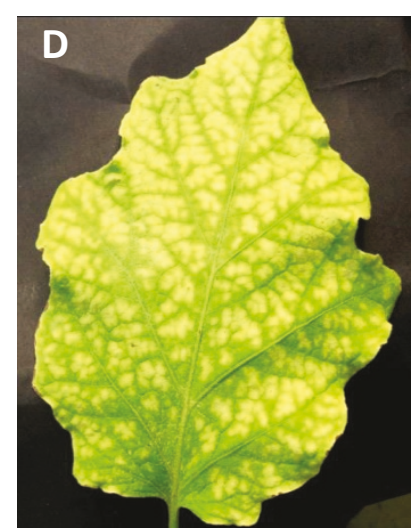

$A+B+\beta$

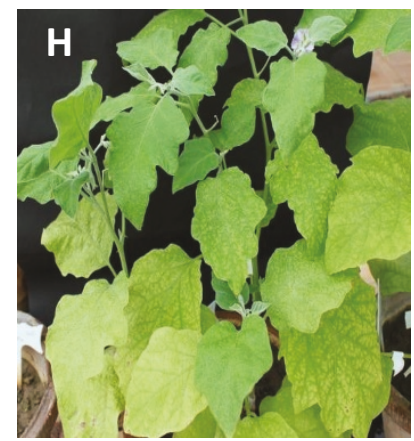

$A+B+\beta$

Figure 4 The disease was induced by ToLCNDV-IN[IN:Nag:Egg:09] in eggplants that were inoculated with different constructs as labeled. The agro-inoculated plants are shown at the bottom panel and the corresponding representative leaves are shown in the top panel in the magnified form to reveal the patterns of disease symptoms at around $90 \mathrm{dpi}$.

till the recent past. However, begomovirus causing EYMD in Thailand have been identified [1,22] although, the etiology of the disease was not satisfied by Koch's postulates. Prominent yellow mosaic symptoms were observed on eggplants in fields during 2009-2010 in Nagpur, India. Virus like symptoms and infestation of whiteflies prompted us to investigate the possible association of begomovirus with the newly emerging disease of eggplant. Our results confirmed the association of a begomovirus with EYMD. Based on high nucleotide sequence identity (97.6\% for DNA-A and 94.1\% for DNA-B) with the strains of ToLCNDV, phylogenetic analysis and the demarcation criteria in species demarcation[1], the begomovirus isolated from diseased eggplant is considered as a variant of ToLCNDV and we suggest the name as ToLCNDV-IN [IN:Nag:Egg:09].

ToLCNDV is an economically important pathogen and found to be associated with various crop plants in India, Pakistan, Thailand and Bangladesh [1]. ToLCNDV has been reported for the first time in India from tomato and it required both DNA-A and
DNA-B for symptom development [2]. Later on, it has been reported from various crops and weeds such as, chili [32], cucurbits [33], potato [34], papaya[35], bittergourd [36], cotton (GenBank Accession number, EF063145) and Solanum nigrum (GenBank Acc. No. AJ620187). As already known, virus isolated from a plant may or may not be the cause of disease unless it satisfies the Koch's postulates and despite a large host range and geographical distribution of ToLCNDV, very few cloned isolates have been shown to be infectious to either experimental plants or the hosts from which they were isolated.

Therefore, to satisfy the Koch's postulates, the infectivity of ToLCNDV-IN[IN:Nag:Egg:09] was established by infiltrating the agroinfectious clones in eggplant. The agroinfiltration in eggplants resulted in the disease symptoms that are similar to those occurred in the virus infected eggplant in fields. Hence, we fulfilled the Koch's postulates and showed for the first time that ToLCNDV-IN[IN:Nag:Egg:09] is responsible for the newly emerging EYMD in central India. 


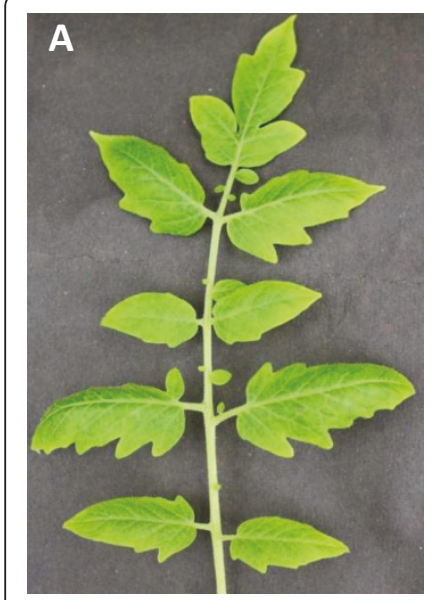

A

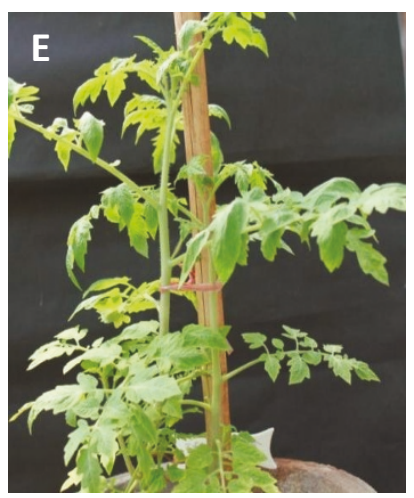

A

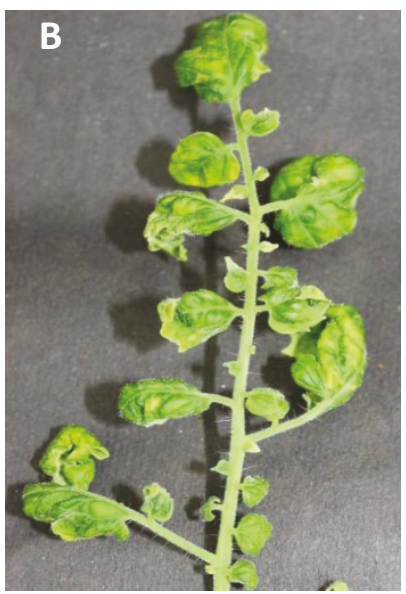

$A+\beta$

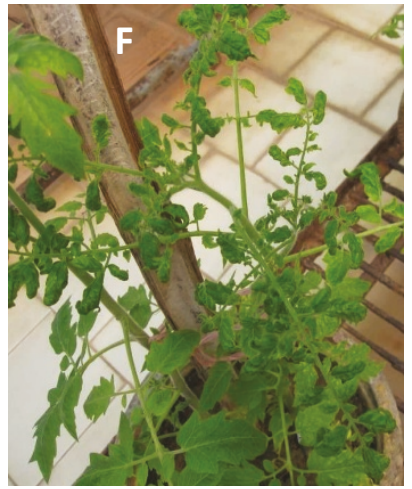

$A+\beta$

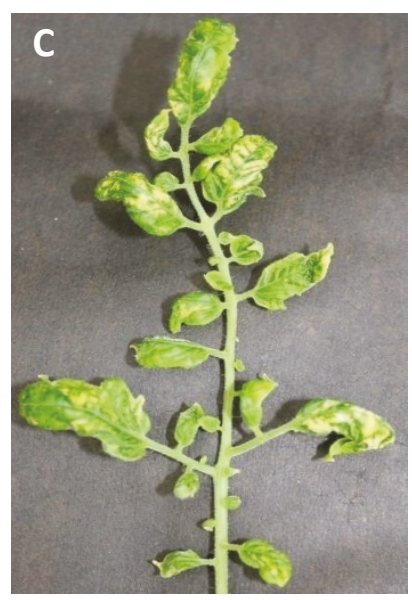

A+B

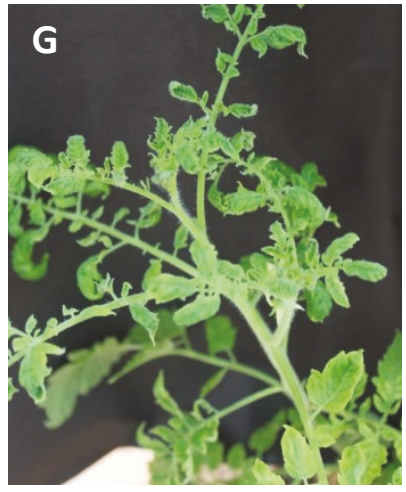

A+B

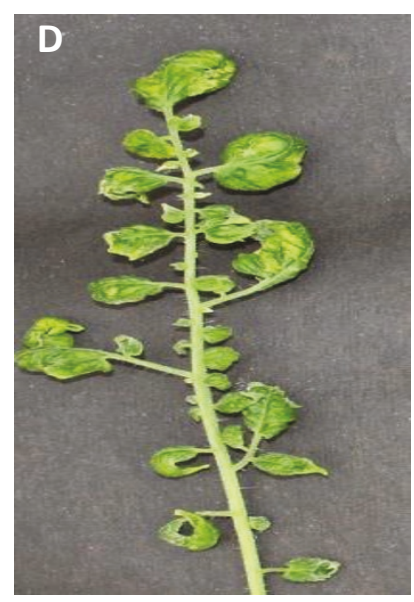

$A+B+\beta$

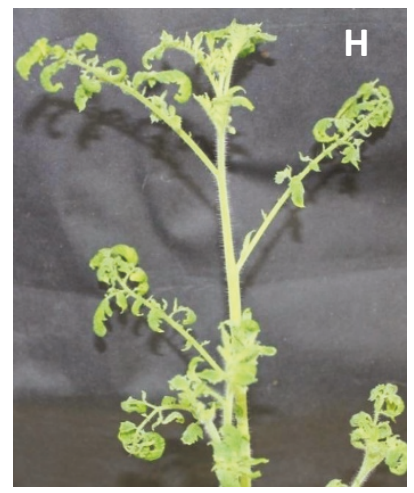

$A+B+\beta$

Figure 5 Plants were inoculated with different constructs as labeled. Rest of the condition is same as described in Figure 4.

Interestingly, ToLCNDV-IN[IN:Nag:Egg:09] gave the typical leaf curling symptoms, not the yellow mosaic in tomato plants. Thus, these results also indicated that the nature of symptoms and disease is largely a host-driven process in this case. The successful virus infection is dependent on productive interactions between viral and host factors at each stage of the infection process and host-adaptation have a different basis in different plants $[37,38]$.

On agroinfiltration with empty vector (taken as negative control) or only DNA-A of ToLCNDV-IN[IN:Nag: Egg:09], no symptoms were recorded even by $180 \mathrm{dpi}$. This showed that DNA-A alone of ToLCNDV-IN[IN: Nag:Egg:09] was neither able to sustain nor produce systemic infection in the host plants. This phenomenon is perhaps true for most of the geminiviruses with the bipartite genomes [2,15].

The association of a DNA- $\beta$ molecule with the field infection of ToLCNDV-IN[IN:Nag: Egg:09] could not be detected by either PCR or RCR method. Nevertheless, we still suspect that in succeeding time, betasatellite associated monopartite begomovirus may be identified with EYMD in southern India. Consequently, we used the non-cognate CLCuMB[IN: ND1:03] molecule to examine its role in degree of virus infection. When CLCuMB[IN: ND1:03] was coinfiltrated with DNA-A of ToLCNDV-IN[IN:Nag: Egg:09], produced mild leaf curling in tomato plants. This result suggested that CLCuMV DNA- $\beta$ can successfully substitute the DNA-B for systemic movement of ToLCNDV-IN[IN:Nag:Egg:09] and symptom development. These results are in conformity with the earlier findings that DNA- $\beta$ can substitute DNA-B for systemic movement [20]. However, the symptoms took longer time to develop and they were mild comparative to that when both the genomic components (DNA-A and DNA-B) were present. It indicated that DNA- $\beta$ can substitute DNA-B up to certain extent but not completely. These results are also in accordance with the previous findings that, DNA-B plays the major role in symptom production and viral pathogenicity in bipartite begomovirus [39]. 
(A)

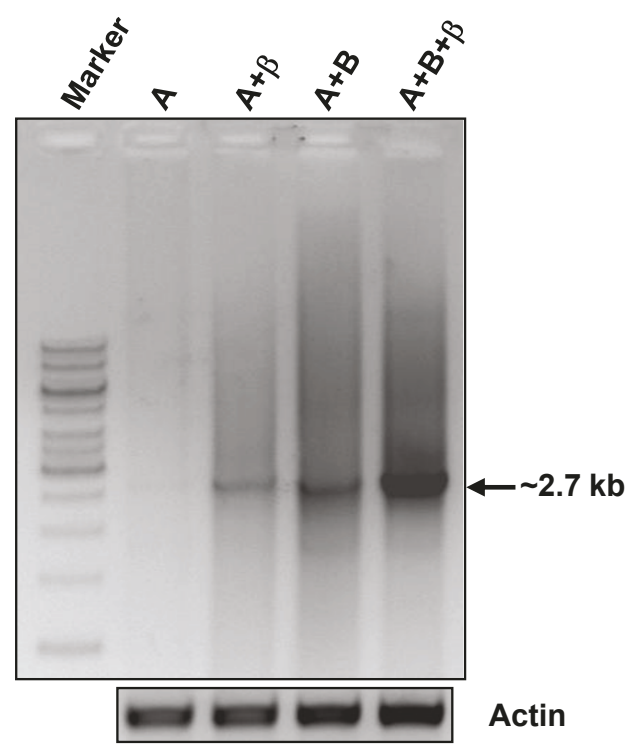

(C)

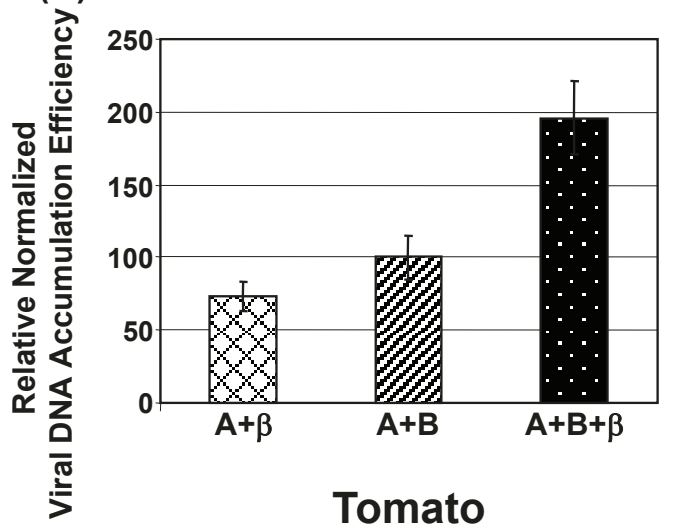

(B)
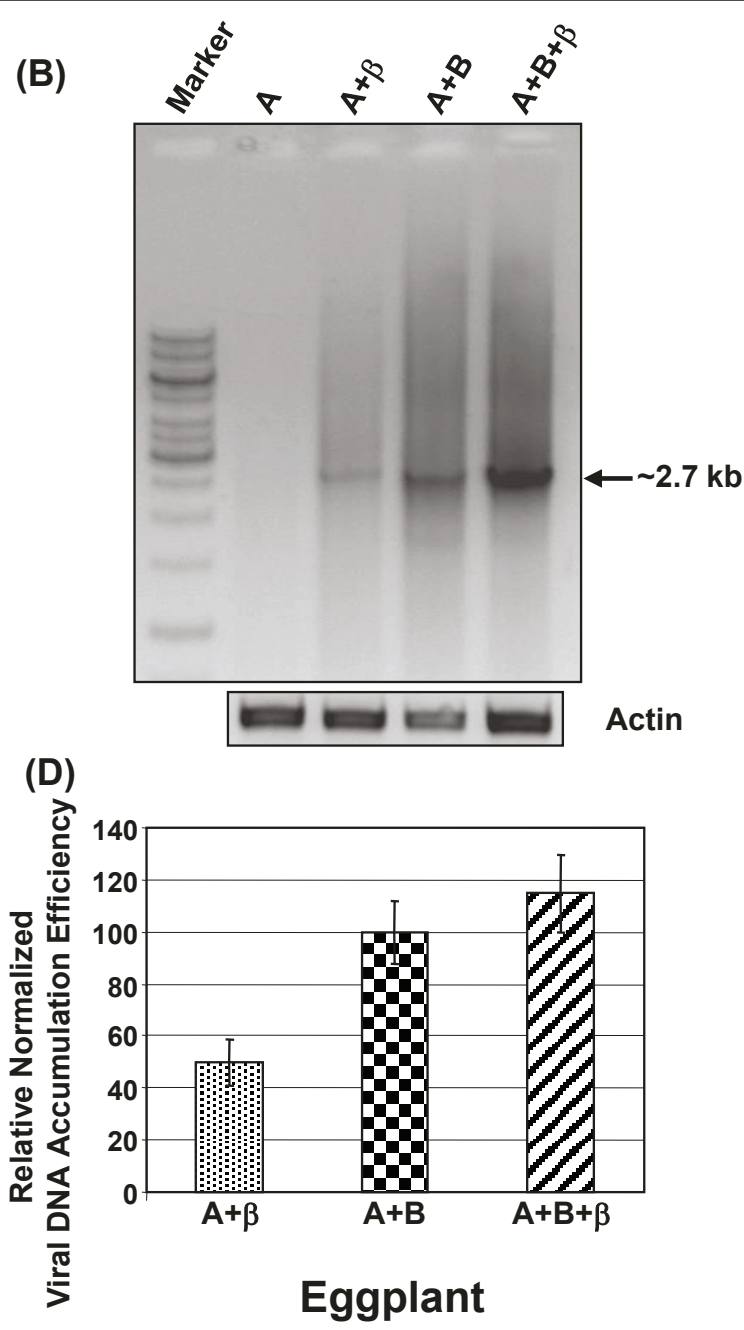

Figure 6 The plants (Tomato and Eggplant) were agro-infiltrated with various constructs as shown on the top of the figures, and the level of viral DNA accumulation was checked by semi-qPCR at 90 dpi using DNA-A specific abutting primers ToLCNDV-IN[IN:Nag:Egg: 09]. The amplification products ( $\sim 2.7 \mathrm{~kb}$ ) were separated on $1 \%$ agarose gel and are presented in panels (a) and (b) for tomato and eggplant respectively. The band intensities were quantified and the normalized values with respect to corresponding loading controls (ACTIN) are plotted as bar graphs in panels (c) and (d) respectively. The standard deviations shown are based on three independent experiments.

The DNA- $\beta$ satellite molecules are also known for intensification of disease symptoms in a host dependent manner $[27,40]$. Co-infiltration of DNA-A and DNA-B of ToLCNDV-IN [IN:Nag:Egg:09] with DNA- $\beta$ of CLCuMV resulted in enhanced severity of disease in both eggplant and tomato. The appearance of disease symptoms also took lesser time compared to that required by both DNA-A and DNA-B. Thus, our results promoted the role of DNA- $\beta$ in increasing the disease severity[41].

The symptomatic variation with agroinfiltrated test plants which were infiltrated with various combinations of constructs were corroborated with molecular findings as the relative virus accumulation of virus increased to about $\sim 95 \%$ and $\sim 14 \%$ in tomato and eggplant respectively when DNA- $\beta$ was infiltrated along with both DNA-A and DNA-B. The value reduced to $\sim 27 \%$ and $\sim 50 \%$ respectively in tomato and eggplant when DNA-B was replaced with DNA- $\beta$, where the value obtained for $A+B$ was arbitrarily assigned as $100 \%$. Furthermore, these results support the notion that DNA- $\beta$ increases the disease severity by increasing the accumulation of the helper virus. The variation observed in tomato and eggplant may be due to the fact that DNA- $\beta$ increased the symptoms severity in a host dependent manner $[14,42]$.

Thus, we have identified and characterized the virus associated with EYMD as a variant of ubiquitous TOLCNDV, but presence of new begomoviruses species with the eggplant cultivation in India cannot be negated 
as different species of monopartite and bipartite begomoviruses exist across India and among them many monopartite begomoviruses with betasatellite molecules are already known to be prevalent in southern India [43]. The diversity of begomovirus may lead to adaptation of eggplants as a new host and as a result the eggplants in other part of India might be under severe threat. Therefore, some practical intervention measures, such as enforcement of quarantine regulations in the trade of live plant materials and development of resistant plants are urgently needed to curb the viral threat.

\section{Conclusion}

Taken together, on the basis of molecular characterization and infectivity test, we can conclude that ToLCNDV-IN[IN:Nag:Egg:09] is a newly emerging variant of ToLCNDV moving to a new economically important host, eggplant and subsequently posing severe constraint on eggplant production in India. This is also a first experimental demonstration of Koch's postulate for a begomovirus associated with eggplant yellow mosaic disease.

\section{Acknowledgements}

We are grateful to Dr. Nirupam Roy Choudhury, ICGEB, New Delhi for helpful discussion and critical reading of the manuscript. We also thank Dr. V. G. Malathi, IARI, New Delhi for CLCuMV betasatellite dimeric clone and Dr. M. K Reddy, ICGEB, New Delhi for pGreen 0029 and pSoup vector.

\section{Author details}

${ }^{1}$ Plant Molecular Biology, International Centre for Genetic Engineering and Biotechnology, Aruna Asaf Ali Marg, New Delhi 110067, India. ${ }^{2}$ Ankur Seeds Private Limited, Nagpur 440018, India.

\section{Authors' contributions}

DP carried out the entire experiments. ARK carried out the survey and collected the infected samples. SKM conceived of the study, DP and SKM participated in designing the experiments. DP and SKM prepared the manuscript. All authors read and approved the final manuscript.

\section{Competing interests}

The authors declare that they have no competing interests.

Received: 3 May 2011 Accepted: 16 June 2011 Published: 16 June 2011

\section{References}

1. Fauquet CM, Briddon RW, Brown JK, Moriones E, Stanley J, Zerbini M, Zhou X: Geminivirus strain demarcation and nomenclature. Archives of Virology 2008, 153:783-821.

2. Padidam M, Beachy RN, Fauquet CM: Tomato leaf curl geminivirus from India has a bipartite genome and coat protein is not essential for infectivity. J Gen Virol 1995, 76(Pt 1):25-35.

3. Brown JK: Current status of Bemisia tabaci as a plant pest and virus vector in agro-ecosystems worldwide. FAO Plant Protection Bulletin (FAO), Bulletin Phytosanitaire de la FAO (FAO); Boletin Fitosanitario de la FAO (FAO) 1994.

4. Czosnek $\mathrm{H}$, Laterrot $\mathrm{H}$ : A worldwide survey of tomato yellow leaf curl viruses. Archives of Virology 1997, 142:1391-1406.

5. Moffat AS: Geminiviruses emerge as serious crop threat. Science 1999, 286:1835-1835.

6. Stanley J: Infectivity of the cloned geminivirus genome requires sequences from both DNAs. 1983.
7. Hanley-Bowdoin L, Settlage SB, Orozco BM, Nagar S, Robertson D: Geminiviruses: models for plant DNA replication, transcription, and cell cycle regulation. Critical Reviews in Plant Sciences 1999, 18:71-106.

8. Pant V, Gupta D, Choudhury NR, Malathi VG, Varma A, Mukherjee SK: Molecular characterization of the Rep protein of the blackgram isolate of Indian mungbean yellow mosaic virus. J Gen Virol 2001, 82:2559-2567.

9. Dry IB, Rigden JE, Krake LR, Mullineaux PM, Rezaian MA: Nucleotide sequence and genome organization of tomato leaf curl geminivirus. Journal of General Virology 1993, 74:147-147.

10. Kheyr-Pour A, Bendahmane M, Matzeit V, Accotto GP, Crespi S, Gronenborn B: Tomato yellow leaf curl virus from sardinia is a whiteflytransmitted monoparatite geminivirus. Nucleic Acids Research 1991, 19:6763-6763.

11. Navot N, Pichersky E, Zeidan M, Zamir D, Czosnek H: Tomato yellow leaf curl virus: a whitefly-transmitted geminivirus with a single genomic component. Virology 1991, 185:151-161.

12. Briddon RW, Markham PG: Cotton leaf curl virus disease. Virus Research 2000, 71:151-159.

13. Briddon RW, Mansoor S, Bedford ID, Pinner MS, Saunders K, Stanley J, Zafar Y, Malik KA, Markham PG: Identification of DNA components required for induction of cotton leaf curl disease. Virology 2001, 285:234-243.

14. Saunders K, Bedford ID, Briddon RW, Markham PG, Wong SM, Stanley J: A unique virus complex causes Ageratum yellow vein disease. Proc Natl Acad Sci USA 2000, 97:6890-6895.

15. Cui X, Li G, Wang D, Hu D, Zhou X: A Begomovirus DNAbeta-encoded protein binds DNA, functions as a suppressor of RNA silencing, and targets the cell nucleus. J Virol 2005, 79:10764-10775.

16. Jose J, Usha R: Bhendi yellow vein mosaic disease in India is caused by association of a DNA [beta] satellite with a Begomovirus. Virology 2003, 305:310-317

17. Saunders K, Salim N, Mali VR, Malathi VG, Briddon R, Markham PG, Stanley J: Characterisation of Sri Lankan cassava mosaic virus and Indian cassava mosaic virus: evidence for acquisition of a DNA B component by a monopartite begomovirus. Virology 2002, 293:63-74

18. Saunders K, Briddon RW, Stanley J: Replication promiscuity of DNA-beta satellites associated with monopartite begomoviruses; deletion mutagenesis of the Ageratum yellow vein virus DNA-beta satellite localizes sequences involved in replication. J Gen Virol 2008, 89:3165-3172.

19. Briddon RW, Bull SE, Amin I, Idris AM, Mansoor S, Bedford ID, Dhawan P, Rishi N, Siwatch SS, Abdel-Salam AM, others: Diversity of DNA [beta], a satellite molecule associated with some monopartite begomoviruses. Virology 2003, 312:106-121.

20. Saeed M, Zafar Y, Randles JW, Rezaian MA: A monopartite begomovirusassociated DNA beta satellite substitutes for the DNA B of a bipartite begomovirus to permit systemic infection. J Gen Virol 2007, 88:2881-2889.

21. Pratap D, Kumar S, Raj SK, Sharma AK: Agrobacterium-mediated transformation of eggplant (Solanum melongena L.) using cotyledon explants and coat protein gene of Cucumber mosaic virus. Indian Journal of Biotechnology 2011, 10:19-24.

22. Green SK, Tsai WS, Shih SL, Rezaian MA, Duangsong U: Molecular characterization of a new Begomovirus associated with tomato yellow leaf curl and eggplant yellow mosaic diseases in Thailand. Plant Disease 2003, 87:446-446.

23. Srivastava KM, Hallan V, Raizada RK, Chandra G, Singh BP, Sane PV: Molecular cloning of Indian tomato leaf curl virus genome following a simple method of concentrating the supercoiled replicative form of viral DNA. J Virol Methods 1995, 51:297-304.

24. Haible D, Kober $\mathrm{S}$, Jeske $\mathrm{H}$ : Rolling circle amplification revolutionizes diagnosis and genomics of geminiviruses. Journal of virological methods 2006, 135:9-16.

25. Briddon RW, Bull SE, Mansoor S, Amin I, Markham PG: Universal primers for the PCR-mediated amplification of DNA beta: a molecule associated with some monopartite begomoviruses. Mol Biotechnol 2002, 20:315-318.

26. Hall TA: BioEdit: a user-friendly biological sequence alignment editor and analysis program for Windows 95/98/NT. 1999, 95-98.

27. Zhou X, Xie Y, Tao X, Zhang Z, Li Z, Fauquet CM: Characterization of DNAbeta associated with begomoviruses in China and evidence for coevolution with their cognate viral DNA-A. J Gen Virol 2003, 84:237-247.

28. Sivalingam PN, Malathi VG, Varma A: Molecular diversity of the DNA-beta satellites associated with tomato leaf curl disease in India. Arch Virol 2010, 155:757-764 
29. Lee MW, Yang Y: Transient expression assay by agroinfiltration of leaves. Methods In molecular biology-Clifton Then Totowa- 2006, 323:225-225.

30. Pandey P, Choudhury NR, Mukherjee SK: A geminiviral amplicon (VA) derived from Tomato leaf curl virus (ToLCV) can replicate in a wide variety of plant species and also acts as a VIGS vector. Virol J 2009, 6:152.

31. Czosnek H, Kheyr-Pour A, Gronenborn B, Remetz E, Zeidan M, Altman A, Rabinowitch HD, Vidavsky S, Kedar N, Gafni Y, others: Replication of tomato yellow leaf curl virus (TYLCV) DNA in agroinoculated leaf discs from selected tomato genotypes. Plant molecular biology 1993, 22:995-1005

32. Hussain M, Mansoor S, Iram S, Zafar Y, Briddon RW: First report of Tomato leaf curl New Delhi virus affecting chilli pepper in Pakistan. Plant pathology 2004, 53:794-794.

33. Ito T, Sharma P, Kittipakorn K, Ikegami M: Complete nucleotide sequence of a new isolate of tomato leaf curl New Delhi virus infecting cucumber, bottle gourd and muskmelon in Thailand. Archives of Virology 2008, 153:611-613.

34. Usharani KS, Surendranath B, Paul-Khurana SM, Garg ID, Malathi VG: Potato leaf curl-a new disease of potato in northern India caused by a strain of Tomato leaf curl New Delhi virus. Plant pathology 2004, 53:235-235.

35. Raj SK, Snehi SK, Khan MS, Singh R, Khan AA: Molecular evidence for association of Tomato leaf curl New Delhi virus with leaf curl disease of papaya (Carica papaya L.) in India. Australas Plant Dis Notes 2008, 3:152-155.

36. Tahir M, Haider MS: First report of Tomato leaf curl New Delhi virus infecting bitter gourd in Pakistan. Plant pathology 2005, 54:807-807.

37. Gillette WK, Meade TJ, Jeffrey JL, Petty ITD: Genetic determinants of hostspecificity in bipartite geminivirus DNA A components. Virology 1998, 251:361-369.

38. Petty IT, Miller CG, Meade-Hash TJ, Schaffer RL: Complementable and noncomplementable host adaptation defects in bipartite geminiviruses. Virology 1995, 212:263-267.

39. Ingham DJ, Pascal E, Lazarowitz SG: Both bipartite geminivirus movement proteins define viral host range, but only BL1 determines viral pathogenicity. Virology 1995, 207:191-204.

40. Li Z, Xie $Y$, Zhou $X$ : Tobacco curly shoot virus DNA $\beta$ is not necessary for infection but intensifies symptoms in a host-dependent manner. Phytopathology 2005, 95:902-908.

41. Nawaz-ul-Rehman MS, Mansoor S, Briddon RW, Fauquet CM: Maintenance of an old world betasatellite by a new world helper begomovirus and possible rapid adaptation of the betasatellite. J Virol 2009, 83:9347-9355.

42. Saunders K, Bedford ID, Stanley J: Pathogenicity of a natural recombinant associated with ageratum yellow vein disease: implications for geminivirus evolution and disease aetiology. Virology 2001, 282:38-47.

43. Chowda Reddy RV, Colvin J, Muniyappa V, Seal S: Diversity and distribution of begomoviruses infecting tomato in India. Archives of virology 2005, 150:845-867.

doi:10.1186/1743-422X-8-305

Cite this article as: Pratap et al:: Molecular characterization and infectivity of a Tomato leaf curl New Delhi virus variant associated with newly emerging yellow mosaic disease of eggplant in India. Virology Journal 2011 8:305.

\section{Submit your next manuscript to BioMed Central and take full advantage of:}

- Convenient online submission

- Thorough peer review

- No space constraints or color figure charges

- Immediate publication on acceptance

- Inclusion in PubMed, CAS, Scopus and Google Scholar

- Research which is freely available for redistribution

Submit your manuscript at www.biomedcentral.com/submit 